\title{
Del comer, el deseo, la palabra y su lugar en la vida Gabriela Ángela Zadra ${ }^{1}$
}

La palabra gastronomía, de origen griego, se ha introducido recientemente en el idioma, y aunque apenas se entienda, ha parecido suave a los oídos franceses que tan pronto como la oyen pronunciar demuestran fisonomías satisfechas y labios con sonrisa de alegría. La separación correspondiente entre la gastronomía, la voracidad y la glotonería, empezó entonces a efectuarse.

J.A.Brillat-Savarin, Fisiología del gusto o Meditaciones de gastronomía trascendente, 1825.

Deseo físico del alma de volver a estar allí,

Mediante un viaje metafisico y carnal,

En un desdoblamiento entre yo y yo mismo...

iAh, comerse el pasado como pan de hambriento,

sin paciencia en los dientes para untarle manteca!

Fernando Pessoa

\section{En un principio}

El Génesis pone como primer pecado comer la fruta prohibida. Que se tratara del Árbol del Bien y del Mal, que la promesa de la serpiente hecha a Eva fuera la de que accedería a un saber igual al saber divino, que este pasaje bíblico haya dado lugar a múltiples interpetaciones, incluída la metafórica, la alegórica, no invalidan el hecho de que se habla de una fruta y de que la primer falta fue comer.

Aquellos que padecen de obesidad, de bulimia o de atracones saben eso: hay correlación entre comer y falta, se sienten culpables. Comen a escondidas, no se animan a hablar de ello, comunican la sensación de estar en pecado, el relato mismo suele estar impregnado de culpa, a veces hasta se asemeja a una confesión: "la comunicación es el pecado", dice Bataille (1981).

Por otra parte, la voluntad es incapaz de hacer algo al respecto. Por más que el sujeto se lo proponga una y mil veces, el impulso se impone más allá de ella.

Son hechos observables, sin embargo la relación entre ellos no es tan clara ni es posible establecerla de forma tan directa.

1. Licenciada en Psicología. Profesora Adjunta. Modelos y Teorías IV: Lacan. Universidad de Palermo. Correspondencia: Mario Bravo 1259. Ciudad Autónoma de Buenos Aires. E-mail: gazadra@fibertel.com.ar 
Psicodebate 5. Psicología, Cultura y Sociedad

Lo que hoy llamamos bulimia, por ejemplo, cumplía una función precisa en los banquetes romanos. Era socialmente admitido que después de la comida se recurriera al vómito para poder seguir comiendo y así no perderse nada del festín.

Santo Tomás dedica un pasaje de la Summa teológica a la gula. Allí la cuestión gira en torno a la diferencia entre la satisfacción de una necesidad (la de alimentarse) y la lujuria (un pecado). ¿Cuándo podemos decir que la necesidad está satisfecha? Esto plantea el problema de la saciedad. ¿Cómo establecer el momento de la saciedad? La escolástica desarrolla sus argumentos: lo deleitable es bueno porque nos hace alimentar, pero ello mismo puede conducirnos al exceso. Comer por puro placer es lujuria.

San Agustín, por su parte, dice que el placer es necesario para comer. Si no obtuviéramos algún placer, por pequeño que fuera, no nos veríamos llevados a ingerir los alimentos.

Tanto uno como otro destacan la necesidad de separar el hambre del deseo de comer, separación entre necesidad y deseo. Si según el dicho popular, el hambre y las ganas de comer pueden juntarse, es porque no son lo mismo. Pero, ¿cuál es la diferencia?

El bulímico cree poder responder a esta pregunta recurriendo al vómito. El vómito es una respuesta. No importa si ya está satisfecho, si lo que está comiendo ya no le gusta, si le hace daño o lo engorda. Total...después lo vomita.

Se trata de un impulso irrefrenable que no brinda placer alguno, que no obedece a un deseo por algún alimento especialmente apetitoso. Aquí nos encontramos en el punto opuesto a aquel en el que se encuentra el goloso. Este último elige, siempre hay algo que lo tienta, se detiene frente al quiosco, frente al plato de masas, frente al menú del restaurante, saborea anticipadamente, se toma su tiempo, disfruta, a veces ostensiblemente; el placer que obtiene es manifiesto.

Brillat-Savarin (2001) evoca con simpatía a esos glotones cuya pasión o cuya competencia se reconoce simplemente en la manera -glotona- en que pronuncian la palabra "está bueno". Hablar es un acto erótico, para Barthes (1987).

Según la fórmula homérica, el goce por parte de los dioses de una vida inmortal, gracias a la posesión de un tipo de sangre imperecedera (o sencillamente ausencia de sangre), implica "no comer pan, no ingerir vino". Dicho sea de paso, el pan supone el alimento humano por excelencia, el símbolo de la civilización; los hombres son "comedores de pan" y comer pan y vivir del fruto del trabajo de la tierra equivale para los griegos a otra manera de decir: ser mortal.

¿Para qué, entonces los dioses se sentarían a la mesa? ¿Para qué alimentarse si su cuerpo inmortal no tiene ninguna necesidad? Por placer. Las divinidades se reúnen para comer por el gusto de la fiesta en sí, por la enorme alegría que el banquete les produce y no realmente por el simple fin de saciar su apetito, de calmar su estómago, de llenar una barriga que supone una verdadera fuente de desgracia para los hombres, llevándolos finalmente a la muerte.

\section{El tiempo y la pulsión}

En los padecimientos mencionados no se trata del placer, no se trata del paladeo goloso -que puede ser compartido-, sino de la devoración angustiosa -que siempre es 
en soledad-. Se abren aquí dos vías para articular la cuestión del placer: el tiempo y la presencia del otro.

El tiempo demorado del placer se opone al tiempo urgido de la angustia. Hay un mínimo de duración exigible para la satisfacción, el tiempo del discurso, el tiempo necesario para el acto de la palabra. Para satisfacerse, habrá que hablar. El acto de la palabra liga la pulsión al significante. La pulsión, al articularse en palabras queda sometida a las leyes de la diacronía, a la temporalidad.

En Inhibición, síntoma y angustia, Freud (1976) une angustia y devoración en el temor a ser devorado por el padre. Cronos comiendo a sus hijos, a los que luego se ve obligado a vomitar, devolviéndolos a la vida y anulando así el acto de la devoración. En la circularidad del tiempo mítico es posible volver atrás, deshacer el acto, eludir sus consecuencias, siempre es posible volver al punto de partida -es lo que intenta la neurosis-. En cambio en la tragedia -como en el discurso analítico- el acto es irreversible en sus consecuencias. La acción se inscribe en un orden temporal sobre el que su agente no tiene poder, sus actos se le escapan, lo sobrepasan. El acto, manifestando posteriormente su significación auténtica, vuelve sobre el sujeto-agente, descubre lo que éste es y lo que realmente ha realizado sin saberlo, -dice Vernant (1987) con respecto a la trama trágica-, y nosotros pensamos en el acto fallido.

El momento en el que surge una palabra en el lugar de otra introduce en nuestra práctica cotidiana -la práctica analítica- una chispa del sentido trágico de la acción humana, perdido hace tantos siglos ya. En ese instante efímero nos atraviesa el relámpago de la intensidad de la tragedia, dándonos la ocasión (quizás única en nuestros tiempos bulímicos) de asumir lo que Vernant (2001) llamaría "responsabilidad trágica": de la palabra dicha no es posible desdecirse, no es posible volver atrás, nos obliga a hacernos responsables de ella.

Por otra parte, la unión de los cuerpos a través de la absorción es la forma de unión más radical con otro, el canibalismo. Para el hombre, alimentarse está unido a la buena voluntad del Otro. Pero no es sólo del pan de la buena voluntad del Otro que el sujeto primitivo tiene que nutrirse, sino directamente del cuerpo de aquél que lo nutre. Desde el inicio sólo es posible alimentarse en el encuentro con el Otro, lo cual implica la incorporación no sólo de alimento, sino fundamentalmente, de palabras.

La misma boca para comer y para besar, y para hablar...

Desde la lactancia, el destete y la fase anal hay crecimiento, y no sólo orgánico. Pero las pulsiones no maduran: entre oralidad y analidad no hay relación de crecimiento alguno, lo que cambia es la posición del sujeto con respecto a la demanda.

Por el hecho de que habla, las necesidades del hombre están sujetas a ser formuladas en palabras, tiene que pedir para encontrar satisfacción. Tiene que hablar para calmar su hambre o su sed. Llamamos "aprender a pedir" a la introducción del niño en la disciplina excremencial.

Ya San Agustín decía que el principal estímulo para aprender a hablar es obtener del otro lo que uno desea. 


\section{Por el lado del lenguaje}

Sin embargo la demanda se refiere a otra cosa que a las satisfacciones que reclama. La fase oral es buena muestra de ello, la demanda es de presencia o de ausencia. La madre tiene el privilegio de otorgar o negar satisfacción. Este lugar de omnipotencia, toda posibilidad, permite transformar todo lo que ella concede o deniega en prueba de amor. Queda así traducida la insatisfacción (inherente a la estructura misma de la demanda) en falta de amor.

Al transformar toda demanda en demanda de amor, se anula la particularidad de todo lo que puede ser otorgado.

La fase oral exige este lugar cavado por la demanda. La tendencia de la boca que tiene hambre se expresa por esa misma boca en una cadena significante. Toda demanda es palabra, invoca. La demanda oral, la demanda más simple, la de ser alimentado, se dirige al Otro que espera. A la demanda de ser nutrido le responde contemporáneamente la de dejarse nutrir. Hay reciprocidad entre sujeto y Otro en el nivel de la demanda. Si el sujeto depende por entero de su demanda al Otro, lo que el Otro demanda depende también del sujeto. Pero reciprocidad no es complementariedad: el ámbito de la alimentación es fuente inagotable de conflicto desde los primeros tiempos de la relación del niño con la madre. El niño sabe muy bien que tiene algo que puede rehusarle a la demanda de la madre.

En esta hendidura entre la demanda de ser nutrido y la de dejarse nutrir aparece la primera diferencia. A la demanda oral la desborda un deseo.

Más allá de lo que el sujeto demanda, más allá de lo que el Otro demanda al sujeto, se encuentra la dimensión de lo que el Otro desea.

\section{En cuanto al deseo}

"Me gusta esto y no aquello". Desde muy pequeños los niños tienen alimentos preferidos y alimentos rechazados. Sabemos cuánto se aferran a estas preferencias y a esos rechazos, y lo rebeldes que son a abandonarlos. Eligen el hambre antes que un alimento que repudian. No admiten sustituciones ni negociaciones. El capricho es el modo de proteger el deseo contra el aplastamiento de la demanda, contra el capricho de la demanda del Otro. El niño caprichoso insiste tenazmente en su demanda más radical, se niega a aceptar las "razones" del Otro. Por paradójico que parezca, se abre allí una posibilidad de corte, de separación; al fin y al cabo parece ser eso lo que reclama a fuerza de insistir en su capricho: el punto donde se ponga de manifiesto la negativa, y con ella, la imposibilidad del Otro, su castración ${ }^{2}$.

2. Pienso ahora en el contrapunto que podría establecerse entre el chico caprichoso y el chico aburrido, por ejemplo. El primero imponiendo (intentando imponer) su deseo en su forma más brutal de condición absoluta -sólo importa lo que él desea, el objeto que demanda es el único objeto que podría satisfacerlo, se le impone (intenta imponerlo) bajo la forma imperiosa de la necesidad; el segundo, entregando totalmente al Otro el saber sobre su deseo: "Mamá, estoy aburrido" es una de las 
Del comer, el deseo, la palabra y su lugar en la vida

La condición absoluta del deseo permite el desasimiento con respecto al Otro. Es lo que plantea Winnicott (1999): el objeto transicional es lo que media, pero a la vez pone corte en la relación primordial con la madre. El osito, la frazadita deshilachada, al recibir por transferencia la exigencia de presencia de la que antes era destinataria la madre, abren la posibilidad de una primera separación.

Allí es donde aparece la especificidad del deseo, la particularidad que había sido abolida retorna aquí. El campo del deseo es el de la pura particularidad: "la crema al costado de las frutillas, no encima", el ámbito de la alimentación es particularmente generoso en ejemplos de esta naturaleza. Todos tenemos nuestras preferencias, nuestros pequeños caprichos.

Es del deseo unido a las palabras de lo que se trata en un análisis. Ello nos compromete a la abstención en cuanto a las respuestas.

El deseo goloso puede surgir ante la sola lectura del menú, no hace falta probar los alimentos, ni siquiera verlos. El deseo despierta por las palabras. En el uso que hace Brillat-Savarin (2001) de las palabras lee Barthes (1987) la huella de un profundo placer, que remite al deseo de la lengua: "Brillat-Savarin desea la palabra como desea las trufas, una tortilla de atún, un pescado a la marinera", afirma.

\section{En cuanto al salmón}

Levi-Strauss (1988) define el goce de ciertos alimentos como necesaria y estructuralmente socializado, introduciendo así la necesidad de la presencia del otro por una vía diferente que el psicoanálisis. Nombra el salmón entre uno de esos alimentos cuya sola aparición provoca su consumo en forma compartida. Lo pone del lado de los bombones y las flores: son bienes que carecen de un valor esencial de consumo, deben adquirirse convenientemente en la forma de donaciones recíprocas más que en las de la compra y del consumo individuales.

Para consumir ciertos productos debemos asegurarnos de la intervención de la cultura, a través de la presencia de los otros. No se puede comerlos a solas sin sentir un vago sentimiento de culpabilidad (Otra vez la culpa...Aunque en este caso, a diferencia de los trastornos en la alimentación, es una culpa que disfruta en su confesión, que necesita ser contada, compartida, hasta quizás, exhibida: “A que no sabés lo que me comí”).

Lacan (1999) ubica en el chiste del "salmón con mayonesa" citado por Freud (1976) en El chiste y su relación con lo inconsciente, la función de la ingratitud: "Un pobre se granjea 25 florines de un conocido suyo de buen pasar, tras protestarle largo tiempo su miseria. Ese mismo día el benefactor lo encuentra ante una fuenta de salmón con

frases temidas por las madres. Y con razón, el objeto que demanda es un saber, la madre tiene que saber lo que el niño desea.

Sin embargo, a pesar de sus diferencias, ambos nos confrontan con lo inadecuado de cualquier respuesta que se otorgue, el resultado será siempre la insatisfacción. En ambos es posible encontrar la presencia de la angustia. 
Psicodebate 5. Psicología, Cultura y Sociedad

mayonesa. Le reprocha: ¿Cómo? Usted consigue mi dinero y luego pide salmón con mayonesa ¿Para eso ha usado mi dinero? Y el inculpado responde: "No lo comprendo a usted; cuando no tengo dinero, no me está permitido comer salmón con mayonesa; cuando tengo dinero, no me está permitido comer salmón con mayonesa. Y entonces, ¿cuándo comería salmón con mayonesa?"

La ingratitud pone un corte en el circuito interminable de la reciprocidad de la demanda, abriendo así el camino al deseo. La falta de agradecimiento -falta al fin- es un modo de no quedar sometido a la pura entrega a la omnipotencia del Otro.

En el sueño de la bella carnicera Freud (1976) interpreta el deseo de tener un deseo insatisfecho, y se pregunta por el sentido de un deseo de esa naturaleza. Esta paciente le pone un nombre a ese deseo en el contenido manifiesto de su sueño: salmón ahumado. A través del trabajo de interpretación surge el nombre del deseo que el salmón ahumado sustituye: caviar. Ella desea caviar, no desea comer caviar. La interpretación aquí no propone ningún objeto al deseo de la paciente, Freud (1976) no nos oculta su asombro por la clase de deseo que aquí se realiza, pero no duda de que hay realización, y que ésta está en la ausencia de satisfacción.

Los deseos no se gastan, no tienen el carácter de impermanencia propia de toda insatisfacción sino que, por el contrario, se sostienen en la estructura simbólica, la cual los mantiene en un cierto nivel de la circulación del significante.

Aquí coinciden la bella histérica y el chiste de Freud (1976) con Levi-Strauss (1988): el salmón (o aquello que es por él sustituído: el caviar) no es algo que uno pueda largarse a comer así como así. El pedigüeño no se priva de consumirlo ni del placer de la respuesta desafiante al Otro, negándose a satisfacer la demanda de agradecimiento; come el salmón, pero en un ámbito prohibido: con el dinero de otro, el dinero destinado para otra cosa.

La propuesta de la bella carnicera es otra: no darse el gusto de caviar implica mantener el deseo de caviar, ¿para qué? para poder seguir hablando de ese deseo -de su deseo, para divertirse, para seguir dando la lata, afirma Lacan (1999); comerlo le taparía la boca, la dejaría sin palabras, y por lo tanto sin deseo. Su deseo la empuja a soñar con el salmón. El trabajo sobre su sueño en el análisis con Freud (1976) le permite seguir hablando de él.

\section{Referencias Bibliográficas}

Barthes, R. (1987). El susurro del lenguaje. Barcelona: Paidós.

Bataille, G. (1981). El culpable. Madrid:Taurus.

Brillat-Savarin, J.A. (2001). Fisiología del gusto. Barcelona: Óptima.

Freud, S. (1976). El chiste y su relación con lo inconsciente. Obras Completas, tomo VIII. Buenos Aires: Amorrortu Editores. 
Del comer, el deseo, la palabra y su lugar en la vida

Freud, S. (1976). Inhibición, síntoma y angustia. Obras Completas, tomo XX. Buenos Aires: Amorrortu Editores.

Freud, S. (1976). La interpretación de los sueños. Obras completas, tomo IV. Buenos Aires: Amorrortu Editores.

Glasman, S. (2003). Esquema constructivo del "grafo". Conjetural, 39.

Lacan, J. (1999). El seminario. Libro 5: Las formaciones del inconsciente. Buenos Aires: Paidós.

Levi-Strauss, C. (1988). Las estructuras elementales del parentesco, Barcelona: Paidós.

Vernant, J.P. (1987). Mito y tragedia en Grecia antigua, Madrid: Taurus.

Vernant, J.P. (2001). El individuo, la muerte y el amor en la antigua Grecia, Barcelona: Paidós.

Winnicott, D.W. (1999). Realidad y juego. Barcelona: Gedisa. 
Psicodebate 5. Psicología, Cultura y Sociedad 